\title{
Precursory scale increase and long-term seismogenesis in California and Northern Mexico
}

\author{
Frank Evison $\left({ }^{1}\right)$ and David Rhoades $\left({ }^{2}\right)$ \\ ${ }^{1}{ }^{1}$ Institute of Geophysics, Victoria University of Wellington, New Zealand \\ ${ }^{(2)}$ Institute of Geological and Nuclear Sciences, Lower Hutt, New Zealand
}

\begin{abstract}
A sudden increase in the scale of seismicity has occurred as a long-term precursor to twelve major earthquakes in California and Northern Mexico. These include all earthquakes along the San Andreas system during 1960-2000 with magnitude $M \geq 6.4$. The full list is as follows: Colorado Delta, 1966, $M$ 6.3; Borrego Mt., 1968, $M$ 6.5; San Fernando, 1971, M 6.6; Brawley, 1979, M 6.4; Mexicali, 1980, M 6.1; Coalinga, 1983, M 6.7; Superstition Hills, 1987, $M$ 6.6; Loma Prieta, 1989, M 7.0; Joshua Tree, 1992, M 6.1; Landers, 1992, M 7.3; Northridge, 1994, $M$ 6.6; Hector Mine, 1999, $M$ 7.1. Such a Precursory Scale Increase $(\psi)$ was inferred from the modelling of longterm seismogenesis as a three-stage faulting process against a background of self-organised criticality. The location, onset-time and level of $\psi$ are predictive of the location, time and magnitude of the future earthquake. Precursory swarms, which occur widely in subduction regions, are a special form of $\psi$; the more general form is here shown to occur frequently in a region of continental transform. Other seismicity precursors, including quiescence and foreshocks, contribute to or modulate the increased seismicity that characterises $\psi$. The area occupied by $\psi$ is small compared with those occupied by the seismicity precursors known as AMR, $M 8$ and LURR. Further work is needed to formulate $\psi$ as a testable hypothesis, and to carry out the appropriate forecasting tests.
\end{abstract}

Key words precursory seismicity - seismogenesis California-Mexico

\section{Introduction}

Anomalies of seismicity are intuitively the most plausible of all proposed earthquake precursors. The universal power-law relating earthquake magnitude and frequency shows that each earthquake of magnitude $M$ has associated with it, in a statistical sense, about three hundred earthquakes of magnitude $M-2.5$ or greater. For

Mailing address: Prof. Frank F. Evison, Institute of Geophysics, Victoria University of Wellington, P.O. Box 600, Wellington, New Zealand; e-mail: Frank.Evison@vuw.ac.nz a shallow earthquake, aftershocks typically provide about one-tenth of these associated smaller earthquakes. Immediate preshocks, commonly known as foreshocks, seldom provide more than a few, and often none at all. What about preshocks occurring over longer time periods, and perhaps larger areas? The $M 8$ model (Kossobokov et al., 1999) and the Accelerating Moment Release (AMR) model (Varnes, 1989; Bowman et al., 1998) are both concerned with preshocks over moderately long time periods and over large areas. Shorter time periods and large areas are specified in the Load/Unload Response Ratio (LURR) model (Yin et al., 2000). In the present study, the time period is the longest so far suggested for a precursory phenomenon (apart from regular recurrence models), while the area is comparatively small. 
Seismicity precursors are also the easiest to study, because of the very large database contained in observatory catalogues. Many workers consider that it simplifies matters to decluster the catalogue, i.e. to remove aftershocks (Reasenberg, 1985), and perhaps other concentrations of small earthquakes as well. In the present study the whole catalogue is used, apart from applying a magnitude threshold in the interest of homogeneity. Earthquake concentrations, including aftershocks, are found to be highly relevant to the understanding of seismogenesis.

Second only to aftershock sequences, the easiest concentration of earthquakes to recognise in many catalogues is the swarm. Swarms are common in the shallow seismicity of subduction regions: systematic studies in New Zealand, Japan and Greece show that swarms make a large contribution to long-term preshock activity in subduction regions, where swarms are predictive of mainshocks (Evison and Rhoades, 2000). This phenomenon is explained by modelling seismogenesis as a three-stage faulting process occurring against a background of self-organised criticality (Evison and Rhoades, 1998, 2001). An inference from the model, however, is that preshocks need not occur as swarms. This has been confirmed in a region of continental collision (Evison and Rhoades, 1999a): the precursor is a long-term set of preshocks, irrespective of how they are distributed in time. The present paper extends the study to a region of continental transform, and better defines the precursor as a sudden increase in the scale of long-term minor seismicity in the neighbourhood of the future mainshock. The aim is to show that the scale increase is a seismogenic phenomenon, preparatory to formulating an hypothesis that can be tested by long-range forecasting.

\section{The $\psi$-phenomenon}

The precursory scale increase, here called the $\psi$-phenomenon, is a seismicity pattern in space, magnitude and time. The essential features of the phenomenon are shown schematically in the three diagrams in fig. 1a-c. First, the area occupied by the phenomenon indicates the location and space-scale of the seismogenic process (fig. 1a). This is found by adjusting the position, size and shape of a rectangular area containing the main-shock and aftershocks, so as to obtain the highest seismicity rate in the precursory period relative to the rate in the prior period (see fig. 1c). Such a procedure could be refined by formal optimisation, which could readily allow for areas to be elliptical, with any orientation, rather than the present N-S, E-W rectangles. For the 12 examples presented below, the median main-shock magnitude is M6.6, and the median area is $4500 \mathrm{~km}^{2}$. All earthquakes that occur in the rectangle (and have magnitudes at or above the threshold) are included in the analysis.

Secondly, the magnitude level $M_{P}$ of the precursory seismicity (fig. 1b) determines the magnitude-and-time scale of the seismogenic process. A robust measure of magnitude level, adopted here as in previous studies of the swarm precursor, is the average of the three largest magnitudes in the relevant time-period. Since much of the precursory seismicity tends to occur early in the precursory period, a good estimate of this magnitude level, which is a crucial seismogenic parameter, is usually available at an early stage.

Thirdly, the jump in seismicity that marks the onset of seismogenesis is indicated by the sudden change of slope in fig. 1c. This graph is a cumulative magnitude anomaly (cumag), $C(t)$, which is a type of cusum (Page, 1954) designed to display the average rate of seismicity between any two points in time. $C(t)$ is defined by

$$
C(t)=\sum_{t_{s} \leq t_{i} \leq t}\left(M_{i}-M_{c}+0.1\right)-k\left(t-t_{s}\right)
$$

$$
k=\sum_{t_{s} \leq t_{i} \leq t_{f}}\left(M_{i}-M_{c}+0.1\right) /\left(t_{f}-t_{s}\right)
$$

where $M_{i}$ is the magnitude and $t_{i}$ the time of the $i$ th earthquake, $M_{c}$ is the threshold magnitude, and $k$ is the average rate of magnitude accumulation between the starting time $t_{s}$ and the finishing time $t_{f}$. Accordingly, each earthquake 

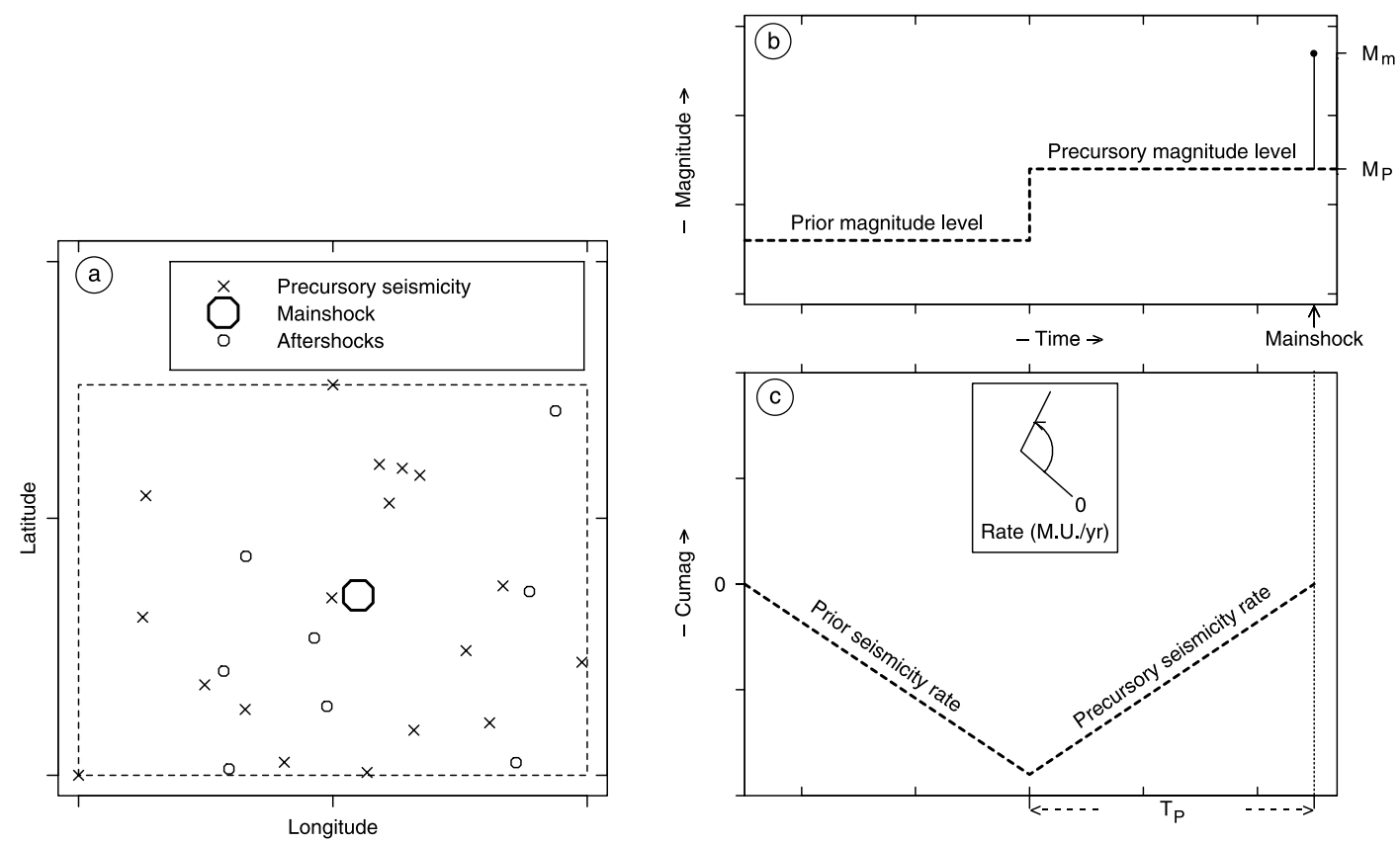

Fig. 1a-c. $\psi$-phenomenon: schematic. a) Typical epicentral area of precursory seismicity, mainshock and aftershocks. b) Prior magnitude level and jump to precursory level $M_{P}$. Magnitude level is derived from the data: it is the average of the three largest magnitudes in the relevant period of time. $M_{m}$ is the mainshock magnitude. c) Prior and precursory seismicity rates, showing sudden change at start of precursor time $T_{P}$. Seismicity rate is derived from the data by means of the cumag (see eqs. (2.1) and (2.2)); it is averaged over the relevant period of time. A protractor is included to indicate the rate corresponding to any given slope; rate is given in units of magnitude above base-level, per year (MU/yr).

throughout the sequence is represented by an upward jump equal to the amount by which the magnitude exceeds the baseline value, which is 0.1 below the threshold magnitude. The downward slope between successive earthquakes is equal and opposite to the sum of all the upward jumps, divided by the total time; thus, a given plot begins and ends at the value zero. Unlike most cusum graphs, the cumag abscissa is a linear scale of time.

From eqs. (2.1) and (2.2) it follows that the gradient of the line between any two points on the $C(t)$ curve is a measure of the average rate of earthquake activity during the corresponding time period. Gradients are translated into seismicity rates by means of a protractor, with seis- micity rate expressed in units of magnitude per year (MU/yr) for the relevant area. (For example, if the chosen threshold magnitude $\left(M_{c}\right)$ is 4.0 , and in a particular interval of a year there occurs a single earthquake, with magnitude 4.9, the seismicity rate for that time interval is 1.0 $\mathrm{MU} / \mathrm{yr}$ ). A major upward jump in rate produces a sharp minimum in the $C(t)$ graph; the low point is taken as the onset of the $\psi$-anomaly, and the date of the low point marks the start of the precursor time $T_{P}$. The precursory rate is then given by the gradient of the straight line joining the low point to the zero point immediately before the mainshock, while the prior rate is obtained by joining the initial zero point to the low point. 


\section{The $\psi$-phenomenon in California and Northern Mexico}

The $\psi$-phenomenon is documented here for twelve major earthquakes in California and Northern Mexico, including all the earthquakes of magnitude $M \geq 6.4$ that occurred along the San Andreas system in the period 1960-2000. This exploratory study is a basis for the future development of a testable hypothesis, and the conduct of formal tests. For the special case of the precursory swarm phenomenon, such tests are already in progress in New Zealand, Japan and Greece (Evison and Rhoades, 1997, 1999b, 2000).

The earthquakes discussed here are the following: Colorado Delta, 1966, M 6.3; Borrego Mt., 1968, M 6.5; San Fernando, 1971, M 6.6; Brawley, 1979, M 6.4; Mexicali, 1980, M 6.1; Coalinga, 1983, M 6.7; Superstition Hills, 1987, $M$ 6.6; Loma Prieta, 1989, M 7.0; Joshua Tree, 1992, M 6.1; Landers, 1992, M 7.3; Northridge, 1994, M 6.6; Hector Mine, 1999, M 7.1. The database used is the CNSS Worldwide Earthquake Catalog, 1954-2000. This Catalog is contributed to by member networks of the U.S. Council of the National Seismic System, and is available from the Northern California Earthquake Data Center. Since magnitude level is here defined by the three largest earthquakes in the relevant time-period, thresholds are adopted which abundantly satisfy the requirements of homogeneity: $M 4.0$ for two of the larger earthquakes, and $M 3.5$ for the rest. The areas within which the phenomenon and associated earthquake occurred are shown in the location map of fig. 2.

The observations are shown in figs. 3i-xii. All the catalogued earthquakes within the indicated space and time windows, and above the magnitude thresholds, are included in the analysis and plotted in the diagrams. No processing such as declustering is applied, nor any transformation of the catalogued magnitudes into moment, energy or Benioff strain release. The length of time preceding the onset is indeterminate on the view of seismogenesis adopted here, but where possible the period before the onset has been taken as about equal to that after. With this standard format a remarkable similarity is

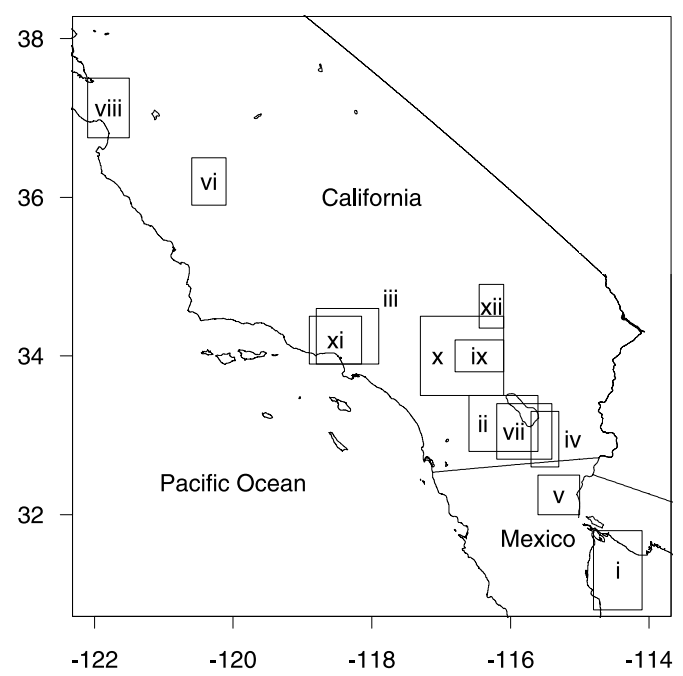

Fig. 2. Areas within which the $\psi$-precursor and associated major earthquake occurred at: i) Colorado Delta; ii) Borrego Mt.; iii) San Fernando; iv) Brawley; v) Mexicali; vi) Coalinga; vii) Superstition Hills; viii) Loma Prieta; ix) Joshua Tree; $x$ ) Landers; xi) Northridge; xii) Hector Mine.

apparent between most of the examples. Shorter pre-onset periods sometimes have to be accepted; this applies both at Borrego Mt. (fig. 3ii), near which a neighbouring earthquake occurred a few years earlier (Rabbit Peak, 1954.03.19, M 6.4), and at Superstition Hills (fig. 3vii), which occurred close to the preceding Brawley earthquake (fig. 3iv).

The essential features of the $\psi$-phenomenon, as shown schematically in fig. 1a-c, are identified in figs. 3i-xii by means of dashed lines. The areas occupied by the phenomenon are typically much smaller than those occupied by some seismicity precursors, including $M 8$ (Kossobokov et al., 1999), AMR (Bowman et al., 1998), and LURR (Yin et al., 2000). In all twelve examples in figs. $3 \mathrm{i}$-xii the data display the sudden increase in the rate of seismicity and the associated increase in magnitude level (figs. 3i-xii(b)). Parameter values are given in table I. The times of the twelve seismicity jumps (i.e. the onset times) are widely 

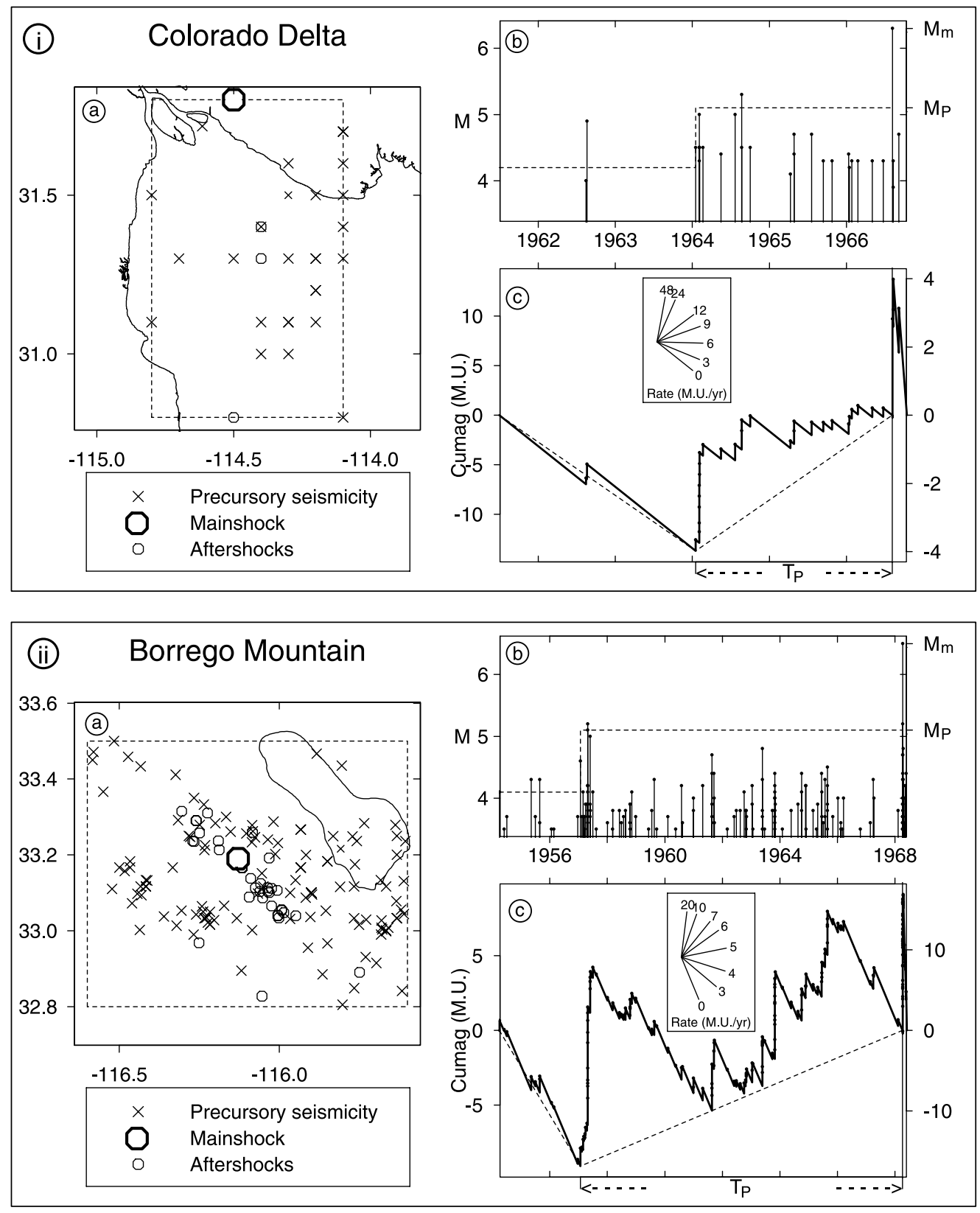

Fig. 3i,ii. $\psi$-phenomenon: data and interpretation for major earthquakes at (i) Colorado Delta and (ii) Borrego Mt. Interpretation is explained in fig.1a-c. a) Epicentres. b) Magnitudes versus time, also showing (dashed lines) the derived prior and precursory magnitude levels. c) Cumag (eqs. (2.1), (2.2)), also showing (dashed lines) the derived prior and precursory seismicity rates. (The cumag scale on the right-hand side refers to the mainshockaftershock period). 

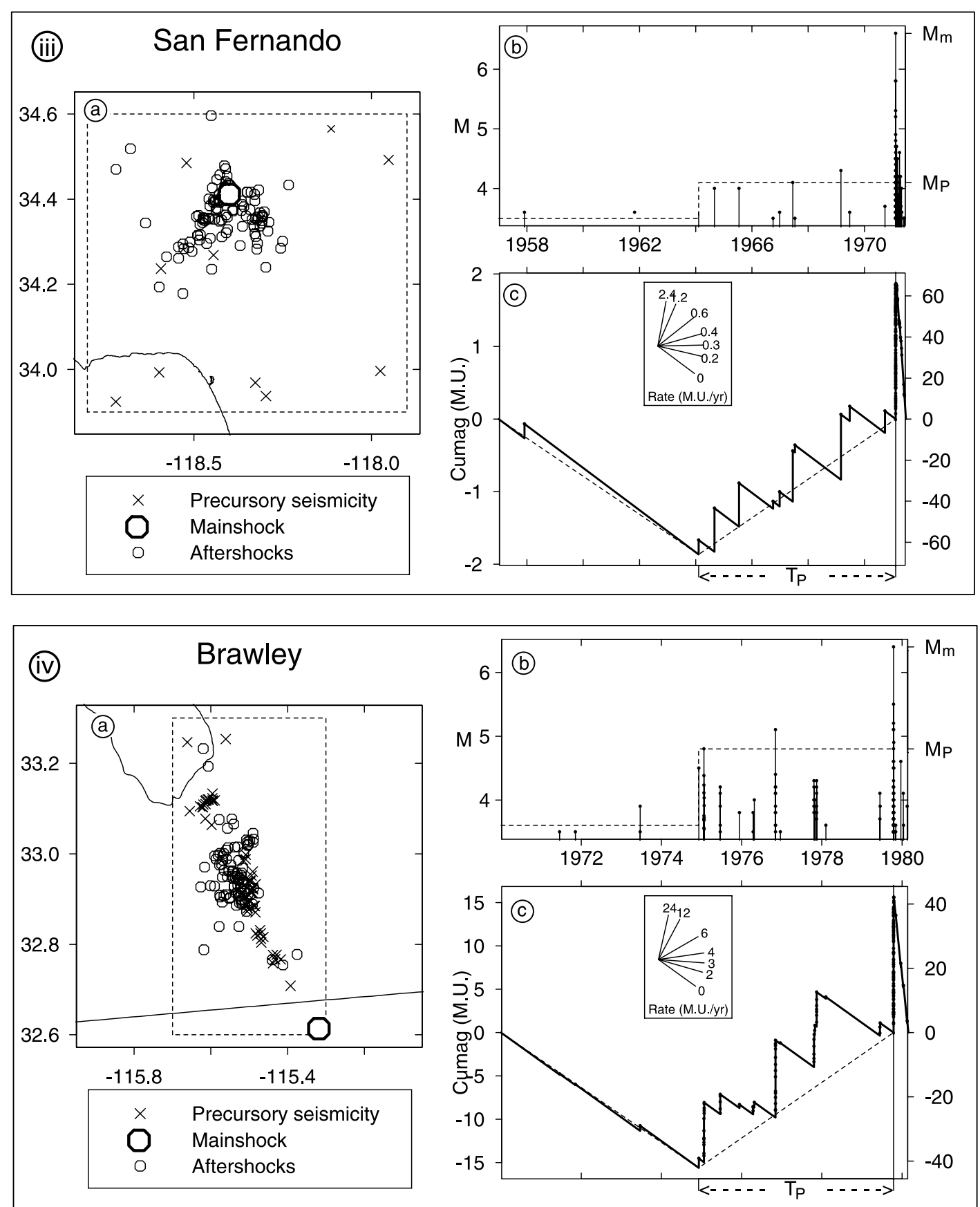

Fig. 3iii,iv. $\psi$-phenomenon: data and interpretation for major earthquakes at (iii) San Fernando and (iv) Brawley. For explanation see caption fig. 3i,ii. 
Precursory scale increase and long-term seismogenesis in California and Northern Mexico
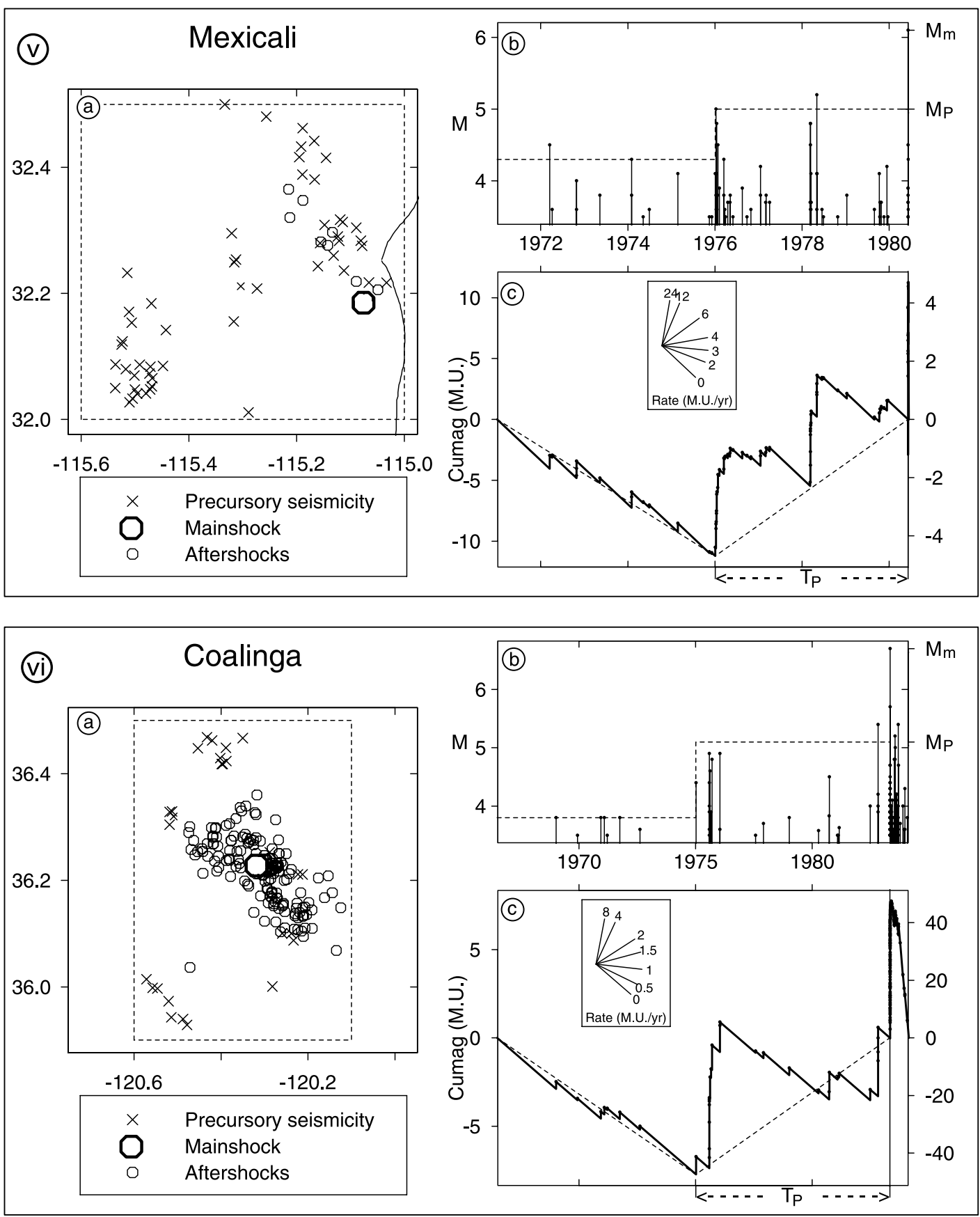

Fig. 3v,vi. $\psi$-phenomenon: data and interpretation for major earthquakes at (v) Mexicali and (vi) Coalinga. For explanation see caption fig. 3 i,ii. 

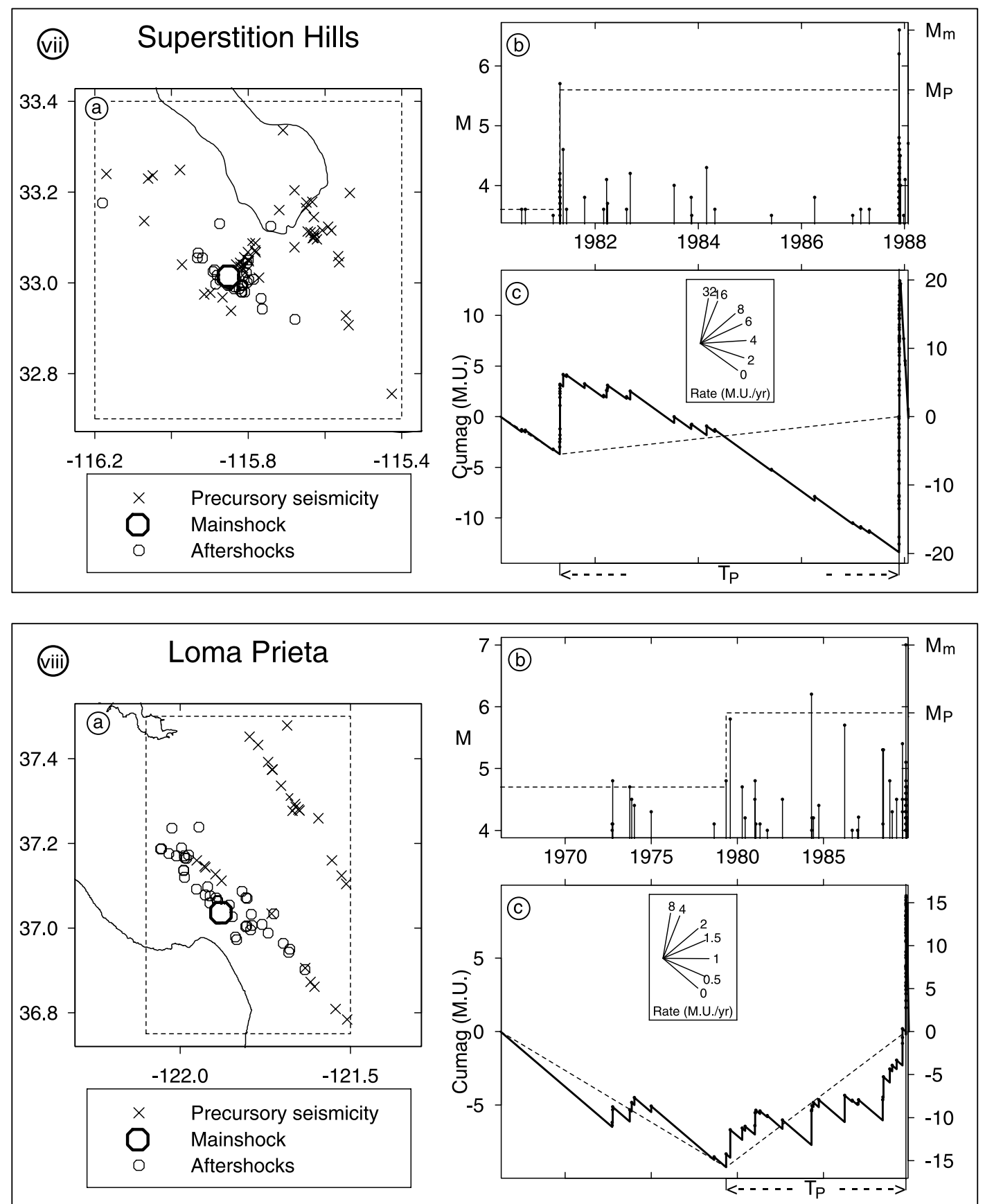

Fig. 3vii,viii. $\psi$-phenomenon: data and interpretation for major earthquakes at (vii) Superstition Hills and (viii) Loma Prieta. For explanation see caption fig. 3i,ii. 
Precursory scale increase and long-term seismogenesis in California and Northern Mexico
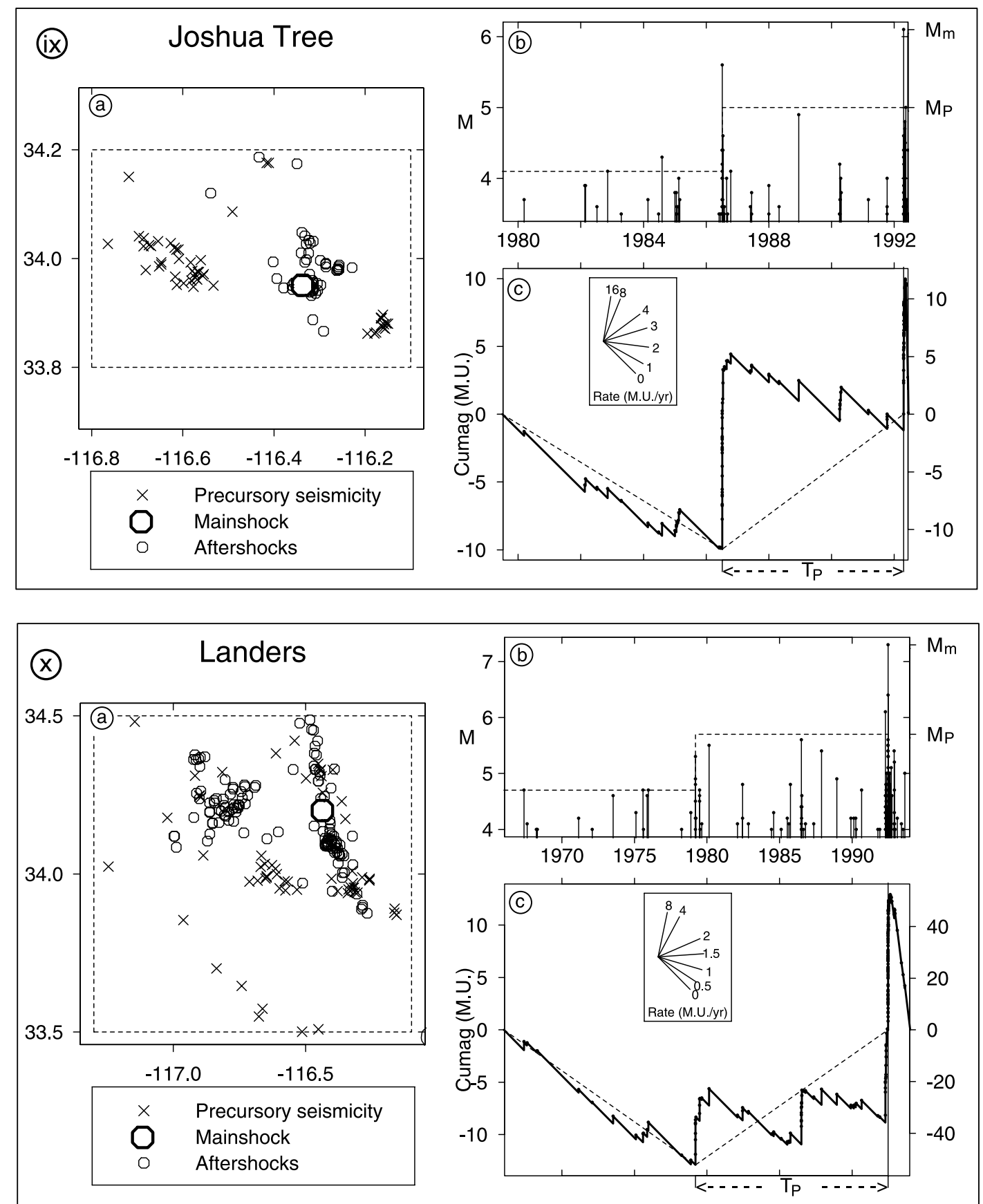

Fig. 3ix,x. $\psi$-phenomenon: data and interpretation for major earthquakes at (ix) Joshua Tree and (x) Landers. For explanation see caption fig. 3i,ii. 

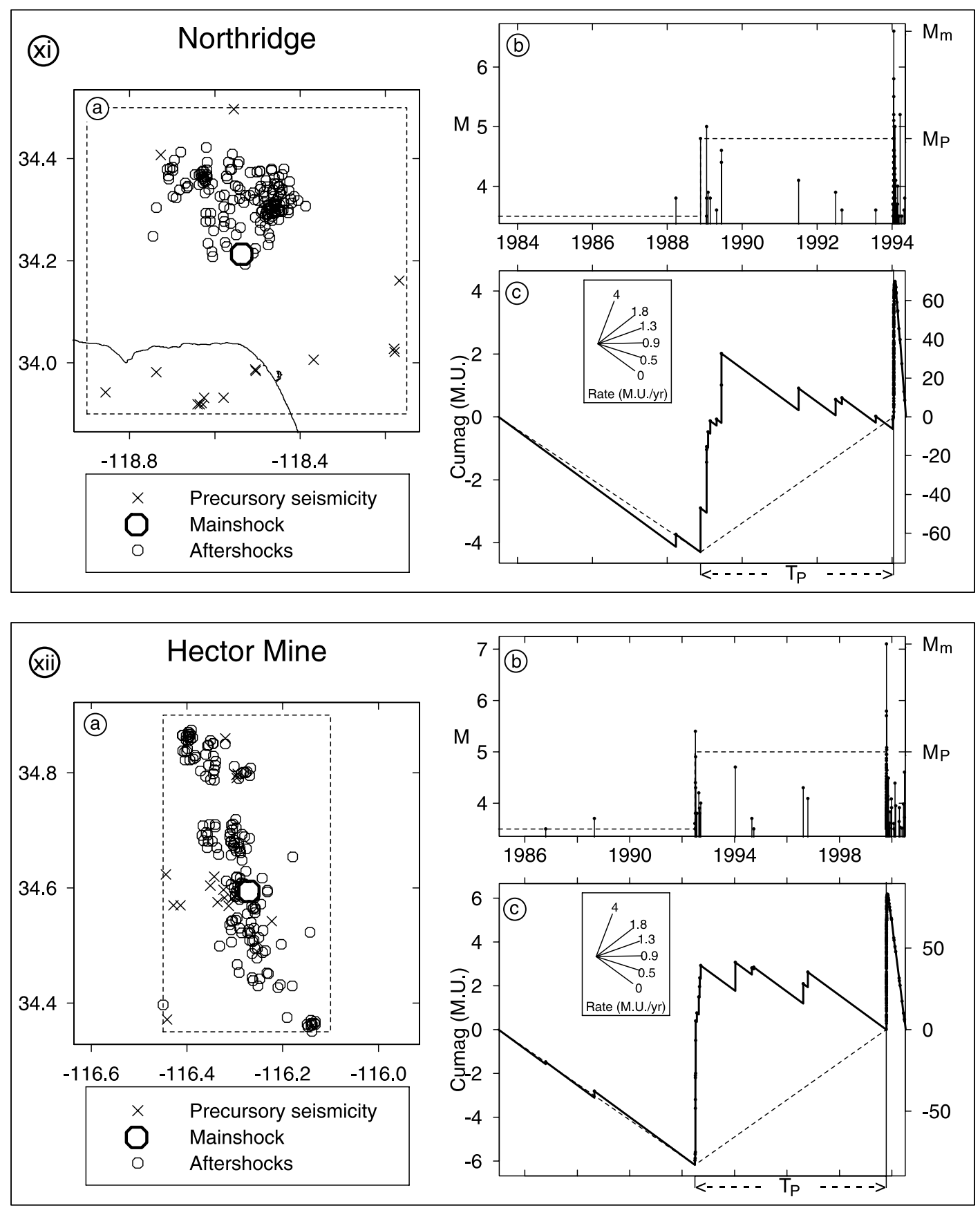

Fig. 3xi,xii. $\psi$-phenomenon: data and interpretation for major earthquakes at (xi) Northridge and (xii) Hector Mine. For explanation see caption fig. 3i,ii. 
Table I. Precursory scale increase $(\psi)$ data.

\begin{tabular}{|c|c|c|c|c|c|c|c|c|c|c|}
\hline \multirow[t]{2}{*}{ Locality } & \multicolumn{2}{|c|}{ Prior } & \multirow{2}{*}{$\begin{array}{c}\text { Onset } \\
\text { Date }\end{array}$} & \multicolumn{3}{|c|}{ Precursory } & \multicolumn{2}{|c|}{$\begin{array}{l}\text { Scale } \\
\text { increase }\end{array}$} & \multicolumn{2}{|c|}{ Mainshock } \\
\hline & $M_{-}$ & Rate & & $M_{P}$ & Rate & $T_{P}(\mathrm{~d})$ & $M$ & Rate & Date & $M_{m}$ \\
\hline Colorado D. & 4.2 & 0.82 & 1964.01.17 & 5.1 & 11.57 & 933 & 0.9 & 14.04 & 1966.08.07 & 6.3 \\
\hline Borrego Mt. & 4.1 & 1.38 & 1957.01 .24 & 5.1 & 5.42 & 4093 & 1.0 & 3.92 & 1968.04 .09 & 6.5 \\
\hline S. Fernando & 3.5 & 0.03 & 1964.02 .08 & 4.1 & 0.56 & 2558 & 0.6 & 19.79 & 1971.02 .09 & 6.6 \\
\hline Brawley & 3.6 & 0.16 & 1974.12 .06 & 4.8 & 6.55 & 1774 & 1.2 & 40.37 & 1979.10 .15 & 6.4 \\
\hline Mexicali & 4.3 & 1.12 & 1976.01 .03 & 5.0 & 5.89 & 1619 & 0.7 & 5.27 & 1980.06 .09 & 6.1 \\
\hline Coalinga & 3.8 & 0.23 & 1975.01 .06 & 5.1 & 2.07 & 3038 & 1.3 & 8.83 & 1983.05 .02 & 6.7 \\
\hline Super. Hills & 3.6 & 0.44 & 1981.04 .25 & 5.6 & 4.22 & 2404 & 2.0 & 9.70 & 1987.11.24 & 6.6 \\
\hline Loma Prieta & 4.7 & 0.30 & 1979.05.08 & 5.9 & 1.89 & 3816 & 1.2 & 6.34 & 1989.10 .18 & 7.0 \\
\hline Joshua Tree & 4.1 & 0.87 & 1986.07.08 & 5.0 & 4.00 & 2116 & 0.9 & 4.61 & 1992.04 .23 & 6.1 \\
\hline Landers & 4.7 & 0.42 & 1979.03 .15 & 5.7 & 2.37 & 4854 & 1.0 & 5.59 & 1992.06 .28 & 7.3 \\
\hline Northridge & 3.5 & 0.07 & 1988.11 .21 & 4.8 & 1.71 & 1883 & 1.3 & 23.00 & 1994.01.17 & 6.6 \\
\hline Hector Mine & 3.5 & 0.05 & 1992.06 .28 & 5.0 & 1.72 & 2667 & 1.5 & 32.29 & 1999.10.16 & 7.1 \\
\hline
\end{tabular}

$N B$ : $M_{-}$is the prior magnitude level; $M_{P}$ is the precursory magnitude level; $T_{P}$ is the time in days between the onset of seismogenesis and the mainshock; scale increase $M$ is $M_{P}$ minus $M_{-}$; scale increase rate is precursory rate/prior rate.

scattered between 1957 and 1992. This makes it unlikely that the $\psi$-phenomenon in California and Northern Mexico could be an artificial effect produced by improvements in the seismograph network.

The scale increase in magnitude ranges from 0.6 to 2.0 magnitude units, with a median of 1.1 . The scale increase in rate ranges from 3.92 to 40.37, with a median of 9.27 . These median values correspond rather closely; for two Gutenberg-Richter sets with $b$-values of unity, a jump of 1.0 magnitude units would correspond to a scale increase of 10 . The wide range of values for each of the measures of scale increase is to be expected, on the present view of seismogenesis, since the level of seismicity in the prior period, like the length of that period, is indeterminate, and has no effect on the seismogenic process. (It should be noted that the rates in table I are not to be compared from one example to another, since they depend on the size of the relevant area, as well as on the adopted threshold magnitude).

In many of the examples the mainshock epicentre is near the centre of the rectangle, but this is not always to be expected, since the hypocentre may occur at any point on the fracture. At Colorado Delta (fig. 3i) and at Brawley (fig. 3iv), the mainshock epicentre is near the edge of the rectangle, while aftershocks are located among the precursory seismicity.

Once the occurrence of a jump in the rate of seismicity indicates that seismogenesis has begun, it is the time of the jump, and the value of the new magnitude level, that allow the parameters of the major earthquake to be estimated, as will be explained below. The precursory rate given in table I is that for the whole precursory period. The rate up to any earlier point can equally be obtained, from the slope of the cumag between the time of the jump and that of the point in question. Thus it is easy to see to what extent the occurrence of a $\psi$-anomaly would become apparent at an early stage, for example if the seismicity were being monitored in real time. The cumags in figs. $3 \mathrm{i}$-xii show that rates that would be observed early in the precursory period are usually higher than the final value; i.e. lines from the low point to intermediate points along the precursory data-plot are usually steeper than the 
dashed line. At Superstition Hills (fig. 3vii), this is so for about the first half of the precursory period, but the $\psi$-anomaly could hardly have been recognised, because of the short time that elapsed between the nearby Brawley earthquake (fig. 3iv) and the change of scale at Superstition Hills. In addition, many of the precursory earthquakes at Superstition Hills occurred as immediate foreshocks, thus adding to the unusual appearance of the cumag graph. (The dashed line in fig. 3 vii(b) (lower), as in the other cumag graphs in figs. $3 i$-xii, indicates the average seismicity rate from the time of the scale increase to immediately before the mainshock). Despite these complications, the parameter values given in table I for Superstition Hills are compatible with those for the other examples.

The precursory earthquakes, like the aftershocks, contribute directly to the set of minor earthquakes associated with the major earthquake. The two contributions appear to be roughly comparable, since the magnitude levels are about the same (Evison and Rhoades, 1998). Together, therefore, they contribute roughly one-fifth of the minor earthquakes that are statistically associated with the mainshock through the GutenbergRichter relation. The remaining four-fifths evidently occur outside the seismogenic locationtime space; in this larger space the mainshock would not stand out as anomalously large.

The following correlations support the view that the $\psi$-anomaly is a seismogenic phenomenon, and suggest how it might be applied to long-range earthquake forecasting.

\section{Predictive correlations}

The $\psi$-phenomenon is related to the major earthquake in location, magnitude and time. The epicentres of the precursory seismicity are located close to those of the mainshock and aftershocks, as shown in figs. 3i-xii(a). Secondly, the relation between mainshock magnitude $\left(M_{m}\right)$ and precursor magnitude $\left(M_{p}\right)$ agrees closely with the regression that has previously been calculated for the swarm phenomenon (fig. 4a). Thirdly, agreement is also evident with the relation between precursor time $\left(T_{P}\right)$ and precursor magnitude (fig. 4b).

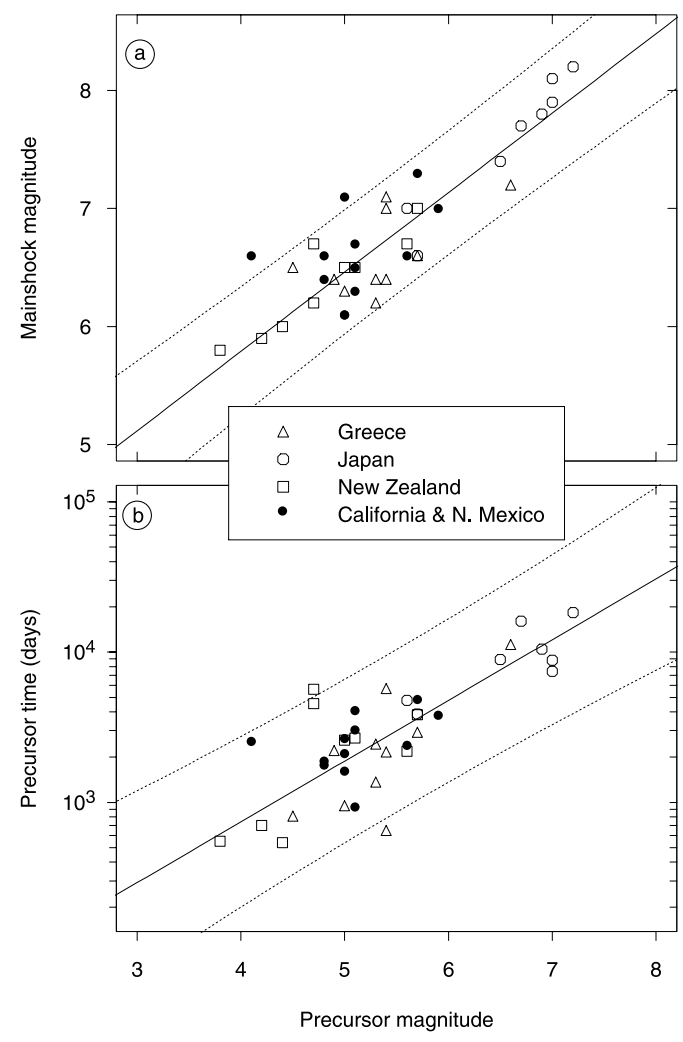

Fig. 4a,b. Predictive regressions (after Evison and Rhoades, 2000) obtained from systematic studies in Greece, Japan and New Zealand, with California and Northern Mexico data superimposed. a) Mainshock magnitude versus precursor magnitude. b) Precursor time versus precursor magnitude. $N B$ : Precursor magnitude and precursor time refer to the special case of the swarm precursor for the Greece, Japan and New Zealand data, and to the more general $\psi$-precursor for the California and Northern Mexico data.

These agreements are to be expected, since precursory swarms are a special form of the $\psi$ phenomenon. The set of precursory earthquakes may occur in a variety of ways. In the shallow subduction regions of Greece, Japan and New Zealand they occur in the highly organized and recognizable form of swarms. In California and Northern Mexico, on the other hand, many different types of distribution occur, as can be seen in figs. 3i-xii. The agreement with regard to 
precursor time depends in part on the tendency of swarms to occur early in the precursory period, i.e. at or soon after the onset of seismogenesis.

Taking the swarm and $\psi$ results together, the relations between precursor and mainshock as regards magnitude and time are now supported, as fig. 4a,b shows, by 40 examples of major earthquakes in New Zealand, Japan, Greece, California and Northern Mexico. The present study has yet to be extended to include a search for instances of the $\psi$-phenomenon occurring unrelated to a mainshock event, or vice versa. Nevertheless, the new results help to sharpen the definition of the $\psi$-phenomenon, and they augment the empirical basis both for testing the predictive capability of the phenomenon and for modelling seismogenesis.

\section{Three-stage faulting model}

A minor variation on the accepted process of faulting - crack formation, shear fracture, healing - is sufficient to account for the above correlations. This variation is to regard crack formation as a stage that is separable in time from the consequent shear fracture. A major fault such as the San Andreas is the result of many such faulting processes through geologic time. As a corollary of the separation of crack formation from shear fracture, it is postulated that a major crack generates a set of minor cracks, in the same way that, in the mainshock/aftershock phenomenon, a major fracture generates a set of minor fractures.

Modelling the faulting process in three separable stages was first proposed to account for the precursory swarm phenomenon (Evison and Rhoades, 1998). An inference from the model, however, was that precursory earthquakes need not occur as swarms. This extended the scope of the long-term seismicity precursor to regions where swarms do not usually occur, i.e. to other than subduction regions. In the continental collision region of New Zealand, swarms are replaced by more dispersed groups of precursory earthquakes, which have been called quasi-swarms, or quarms (Evison and Rhoades, 1999a). The present study is the first in which a sudden increase in the scale of seis- micity is taken as the precursor; this is the most general form suggested by the model.

Under the three-stage faulting model, the formation of a major crack starts the process which eventually culminates in a major shear fracture (and the resultant major earthquake). The major crack at once generates a set of minor aftercracks, which fracture over time, and it is these minor fractures that produce the precursory seismicity. Healing of the set of minor fractures is a necessary condition for the fracture of the major crack, which generates the mainshock and aftershocks. Finally, healing of these fractures restores the medium to the condition it was in before the particular process started.

Three-stage faulting accounts, then, for the following features of the $\psi$-phenomenon. The jump increase in seismicity marks the onset of fracturing of the set of aftercracks generated by the major crack. It has been observed that the set of precursory earthquakes has a similar magnitude level to the aftershocks (Evison and Rhoades, 1998); this follows, in the model, from the major crack and fracture being necessarily of the same size. (In the 12 examples presented here the ratio of aftershock to precursor magnitude level ranges from 0.84 to 1.37 , with a median of 0.99). The long duration of the seismogenic process is explained by the need, according to Mogi's (1963) criteria, for the stress field across a fault to become uniform before fracture can occur; uniformity across the major crack is attained by the healing of the set of aftercracks, after they have fractured and generated the precursory earthquakes. Finally, the essential independence of major earthquakes from one another is explained by the healing which follows the mainshock and aftershocks. Inter-earthquake triggering, while not excluded, occurs as a second-order effect. The failure of experiments based on the regular-recurrence hypothesis, such as the experiment at Parkfield, California (Roeloffs and Langbein, 1994), is explained.

The seismogenic process as modelled by three-stage faulting is further elucidated by the proposal that it takes place against a background of self-organised criticality (Evison and Rhoades, 2001). Self-Organised Criticality (SOC) systems display an extreme sensitivity to initial con- 
ditions. Thus under the model it is acknowledged that the sudden increase in seismicity may be the earliest recognisable signal of a future major earthquake, just as in meteorology, where SOC is the widely accepted background condition, a tropical depression is the earliest signal of a future tropical cyclone. The scaling principle, which is also basic to SOC, is exemplified in the model by the role of the major crack in determining the scale of the entire seismogenic process, with regard to space, magnitude and time. Thus the term «major» is purely relative: the major crack can be of any absolute size. Again, the SOC principle of hierarchy is exemplified in the occurrence of smaller seismogenic processes embedded in larger ones, as with the Joshua Tree process (fig. 3ix), which was entirely embedded in the precursor to the Landers earthquake (fig. 3x).

More generally, the context of a given major earthquake can be understood in two distinct ways, depending on scale. On the larger scale, as already mentioned above, the earthquake belongs to a Gutenberg-Richter set, and occurs in a context of self-similarity. On the smaller scale, the earthquake is anomalous: as a mainshock, it is too large to belong to the GutenbergRichter set of its preshocks and aftershocks. This is the scale of the predictive correlations that have been presented above.

Under self-organized criticality, one can visualise that any of a large number of small earthquakes has the potential to avalanche, thus nucleating a large earthquake. This has been interpreted to mean that individual earthquakes are intrinsically unpredictable. The present model reconciles long-range forecasting with selforganized criticality by accommodating the avalanche-nucleation concept at the crackformation stage of seismogenesis. There is no reason to regard the initial cracking as predictable, but once it has occurred the remaining stages, including the major earthquake, are determined.

This is somewhat analogous to the nucleation and development of a tropical cyclone.

\section{Associated precursors}

Several types of precursor occur as fluctuations which modulate the average seismicity during the precursory period. Large swarms mark the onset of seismogenesis at Colorado Delta (fig. 3i) and Borrego Mt. (fig. 3ii). Foreshocks occur at the end of the precursory period, occasionally in large numbers, as at Superstition Hills (fig. 3vii) and at Landers (fig. 3x). In contrast, quiescence frequently occurs, as at Northridge (fig. 3xi) and Hector Mine (fig. 3xii), in both of which an interval occupying about $40 \%$ of the precursory period was devoid of earthquakes. The well-known accelerating moment release precursor will be discussed in detail below.

A seismicity parameter frequently studied in the context of precursory phenomena is the $b$-value in the Gutenberg-Richter equation $\log _{10} N(M)=a-b M$. A related parameter is the mean magnitude of a Gutenberg-Richter set (Aki, 1965). The Loma Prieta and Northridge earthquakes have been studied by Smith (1998) in terms of precursory changes in mean magnitude. The areas considered are similar to those in fig. 3viii and fig. 3xi. Using two different types of cusum graph, Smith found an anomaly before the Loma Prieta earthquake, beginning at about the same time as the $\psi$-anomaly reported above. This may be a coincidence, since $\psi$ anomalies are closely related to the $a$-value in the Gutenberg-Richter equation, and this is usually held to be independent of the $b$-value.

Precursors involving phenomena other than seismicity may in some cases be compatible with the present model. The crack-formation stage of faulting may produce anomalies in acoustic emission (Scholz, 1990), and coda $Q^{-1}$ (Jin and Aki, 1989), due to a form of dilatancy. Here, the dilatancy will consist of a fractal set of cracks, rather than pores of more or less uniform size. Electromagnetic emissions, too, have been widely reported in association with cracking (e.g., Guo et al., 1994). On the present model, all such crackrelated anomalies are to be looked for early in the precursory period.

Many of these precursors have been observed, but the reporting of examples remains largely anecdotal. This is consistent with the three-stage faulting model. The contributory precursors involving seismicity are possible but not necessary under this model; further, most studies of precursors related to cracking have concentrated on time periods rather close to the mainshock time. 


\section{7. $\psi$ and AMR precursors}

Contrasting interpretations of the seismicity preceding major earthquakes are suggested by the $y$ and AMR (Accelerating Moment Release) patterns. A ready comparison can be made between these interpretations for California, since, of the earthquakes discussed above, Bowman et al. (1998) have presented detailed AMR interpretations of Borrego Mountain, San Fernando, Coalinga, Superstition Hills, Loma Prieta, Landers, and Northridge. The two studies have different backgrounds. The AMR study was a search for empirical support of a theoretical model. The incentive for the $\psi$ study, on the other hand, was an inference from the three-stage faulting model, which was itself developed to explain the precursory swarm phenomenon.

Widely differing areas around the earthquake source are involved in the two interpretations. In AMR theory, an increasing correlation length in the regional stress field reaches a critical point, and this is when the earthquake occurs. The process involves an area very much larger than the earthquake source area. In the case of $\psi$, by contrast, a three-stage faulting process is postulated in the more immediate neighbourhood of the source area, although still involving faults besides that on which the major earthquake occurs. Figure 5 shows the areas of the AMR circles in Bowman et al. (1998) and those of the $\psi$ rectangles, for the same set of earthquakes. Also shown is Utsu's (1961) relation between aftershock area and mainshock magnitude, and parallel lines are fitted to the AMR and $\psi$ sets of data. Overall, the $\psi$ areas are 10 times larger, and the AMR areas 140 times larger, than the aftershock areas. Further, the scatter is considerably less for the $\psi$ areas (variance 0.07 ) than for the AMR areas (variance 0.25).

One might think that the AMR phenomenon would extend into the source region, but according to Jaumé and Sykes (1999) it occurs primarily outside. That no vestige of accelerating seismicity occurs in most of the $\psi$ plots (figs. 3i-xii) is thus only to be expected. The exceptions are Superstition Hills (fig. 3vii), Loma Prieta (fig. 3viii), and Landers (fig. 3x). These apparent occurrences of accelerating seismicity were not identified as AMR by Bowman et al. (1998), who

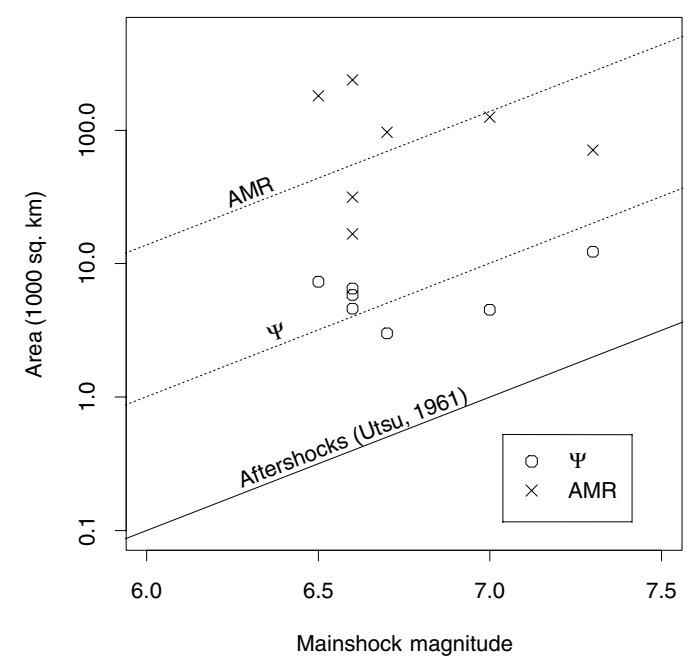

Fig. 5. $\psi$ and AMR precursory areas versus mainshock magnitudes for the earthquakes at Borrego Mountain (1968, M 6.5); San Fernando (1971, M 6.6); Coalinga (1983, M 6.7); Superstition Hills (1987, $M$ 6.6); Loma Prieta (1989, M 7.0); Landers (1992, M 7.3), and Northridge (1994, M 6.6). The Utsu (1961) relation between aftershock area and mainshock magnitude is shown for comparison, and parallel lines are fitted to the AMR and $\psi$ data.

showed (their fig. 5) that for all the earthquakes that they studied, except Loma Prieta, a linear or decelerating moment release was indicated for areas of intermediate size.

Widely differing distributions of the precursory seismicity with respect to time are also proposed by the two models. In AMR, the increase in seismicity is initially emergent, and accelerates up to the time of the earthquake, while in $\psi$, the jump in seismicity occurs at the start of the precursory period. This dominant feature of $\psi$ seems to be irrelevant to AMR, since in the plots given by Bowman et al. (1998, fig. 6) for the Borrego Mountain, San Fernando, Coalinga, Superstition Hills and Northridge earthquakes, the starting date was later than the $\psi$ jump in seismicity.

Little in common can thus be found between the $\psi$ and AMR precursors. They may nevertheless offer complementary information on the location, magnitude and time of future major 
earthquakes. As regards location, the much larger areas involved in AMR are nevertheless centred, in the study by Bowman et al. (1998), on the earthquake epicentre. Robinson (2000) has shown, however, in a study of three New Zealand earthquakes, that the AMR centre was best placed at a distance of 50-60 km from the earthquake epicentre. As regards magnitude, AMR relates this to area, but as shown in fig. 5 above, there is much scatter in magnitude as a function of area. In the $\psi$ precursor, the mainshock epicentre can be anywhere in the rectangular area, as discussed above and exemplified in figs. 3i-xii(a), while the magnitude is given as a probability distribution, with scatter as shown in fig. $4 a$.

The time of the major earthquake is indicated in AMR by an exponentially increasing function of the time to failure. This seems superior to the probability distribution and scatter obtained for the $\psi$-precursor (fig. 4b). But according to Robinson (2000) the earthquake time estimated by AMR is in practice only loosely constrained.

\section{Conclusions}

The $\psi$-phenomenon is one of the simplest earthquake precursors so far identified. It is manifested in the origin times, locations and magnitudes routinely listed in earthquake catalogues. The predictive parameters that it supplies consist of a rather closely defined area, a date, and a magnitude, and these give longterm estimates, in the form of probability distributions, of the location, time and magnitude of the major earthquake. As the longest-term of all suggested precursors (unless one includes the hypothesised «seismic gap» as a precursor), it accommodates a variety of shorter-term anomalies. Precursory swarms, when they occur, are a special case of the $\psi$-precursor. Thus the above examples from California and Northern Mexico can be added to the 28 examples previously published from Japan, Greece and New Zealand, making in all 40 large earthquakes that are similarly related to the $\psi$-precursor. This constitutes a clear description of the $\psi$-phenomenon as a long-term precursor, and part of the seismogenic process, in some of the main types of seismotectonic environment. Formulation of a testable hypothesis can now proceed, and by means of the appropriate methodology (Rhoades and Evison 1979, 1993) the $\psi$-precursor in $\mathrm{Ca}$ lifornia, Northern Mexico and elsewhere can be evaluated for possible use in long-range earthquake forecasting.

\section{Acknowledgements}

The authors thank E.G.C. Smith, W. D. Smith and J.J. Taber for critical readings of the manuscript, and Paolo Gasperini and an anonymous reviewer for valuable comments. The work has been supported by the New Zealand Foundation for Research, Science and Technology, under Contract C05X0006. The first author acknowledges facilities provided under an Honorary Fellowship at Victoria University of Wellington.

\section{REFERENCES}

AKI, K. (1965): Maximum likelihood estimate of $b$ in the formula $\log N=a-b M$ and its confidence limits, Bull. Earthquake Res. Inst. Univ. Toyko, 43, 237-239.

Bowman, D.D., G. OuIllon, C.G. SAmmis, A. Sornette and D. SORNETTE (1998): An observational test of the critical earthquake concept, J. Geophys. Res., 103, 24,359-24,372.

EVISON, F.F. and D.A. RHOADES (1997): The precursory earthquake swarm in New Zealand: hypothesis tests II, N. Z. J. Geol. Geophys., 40, 537-547.

Evison, F.F. and D.A. RHOAdES (1998): Long-term seismogenic process for major earthquakes in subduction zones, Phys. Earth Planet. Inter, 108, 185-199.

EVISON, F.F. and D.A. RHOADES (1999a): The precursory earthquake swarm and the inferred precursory quarm, N. Z. J. Geol. Geophys., 42, 229-236.

EVISON, F.F. and D.A. RHOADES (1999b): The precursory earthquake swarm in Japan: hypothesis test, Earth Planets Space, 51, 1267-1277.

EVISON, F.F. and D.A. RHOADES (2000): The precursory earthquake swarm in Greece, Ann. Geofis., 43(5), 991-1009.

EVISON, F.F. and D.A. RHOADES (2001): Model of long-term seismogenesis, Ann. Geofis., 44 (1), 81-93.

GuO, Z., B. LIU and Y. WANG (1994): Mechanism of electromagnetic emissions associated with microscopic and macroscopic cracking in rocks, in Electromagnetic Phenomena Related to Earthquake Prediction, edited by M. HAYAKAWA and Y. FuJINAWA (Terra Scientific Publishing Co., Tokyo), 523-529.

JAUME, S.C. and L.R. SYKES (1999): Evolving towards a critical point: a review of accelerating seismic moment/ energy release prior to large and great earthquakes, Pure Appl. Geophys., 155, 279-305. 
JIN, A. and K. AKI (1989): Spatial and temporal correlation between coda $Q^{-1}$ and seismicity and its physical mechanism, J. Geophys. Res., 94, 14,041-14,054.

KossoBoKov, V.G., L.L. ROMASHKOVA, V.I. KEYLIS-BOROK and J.H. HEALY (1999): Testing earthquake prediction algorithms: statistically significant advance prediction of the largest earthquakes in the Circum-Pacific, 19921997, Phys. Earth Planet. Int., 111, 187-196.

Mogi, K. (1963): Some discussions on aftershocks, foreshocks and earthquake swarms - the fracture of a semi-infinite body caused by an inner stress origin and its relation to the earthquake phenomena, Bull. Earthquake Res. Inst., 41, 615-658.

PAGE, E.S. (1954): Continuous inspection schemes, Biometrika, 41, 100-114.

REASENBERG, P. (1985): Second-order moment of central California seismicity, 1969-1982, J. Geophys. Res., 90, 5479-5495.

RHoAdES, D.A. and F.F. Evison (1979): Long-range earthquake forecasting based on a single predictor, Geophys. J. R. Astron. Soc., 59, 43-56.

RHoAdES, D.A. and F.F. Evison (1993): Long-range earthquake forecasting based on a single predictor with clustering, Geophys. J. Int., 113, 371-381.
ROBINSON, R. (2000): A test of the precursory accelerating moment release model on some recent New Zealand earthquakes, Geophys. J. Int., 140, 568-576.

RoELOFFS, E. and J. LANGBEIN (1994): The earthquake prediction experiment at Parkfield, California, Rev. Geophys., 32, 315-336.

SCHOLZ, C.H. (1990): The Mechanics of Earthquakes and Faulting (Cambridge University Press, Cambridge), p. 21.

SMITH, W.D. (1998): Resolution and significance assessment of precursory changes in mean earthquake magnitudes, Geophys. J. Int., 135, 515-522.

UTSU, T. (1961): A statistical study on the occurrence of aftershocks, Geophys. Mag., 30, 521-605.

VARNES, D.J. (1989): Predicting earthquakes by analysing accelerating precursory seismic activity, Pure Appl. Geophys., 130, 661-686.

YIN, X.C., Y.C. WANG, K.Y. PENG, Y.L. BAI, H.T. WANG and X.F. YIN (2000): Development of a new approach to earthquake prediction: Load/Unload Response Ratio (LURR) theory, Pure Appl. Geophys., 157 2365-2383.

(received February 4, 2002 . accepted July 4, 2002) 